\title{
An assessment of the severity, proportionality and risk of mortality of very low birth weight infants with fetal growth restriction. A multicenter South American analysis
}

\author{
Carlos Grandi, ${ }^{1}$ José L. Tapia, ${ }^{2}$ Guillermo Marshall, ${ }^{3}$ NEOCOSUR Collaborative Group ${ }^{4}$
}

\begin{abstract}
Objectives: To evaluate the clinical severity and proportionality of small for gestational age, very low birth weight neonates $(<1,500 \mathrm{~g})$ and to estimate the neonatal mortality risk associated with the condition of being small for gestational age according to the degree of severity and proportionality.

Methods: Observational design. All of the NEOCOSUR Collaborative Group's very low birth weight infants (25-36 weeks' gestation) were included $(n=1,518)$. Anthropometric indices: birth weight $<3$ rd and 10th percentile. Severity (fetal growth ratio = observed weight/mean birth weight for gestational age); no growth restriction: fetal growth ratio $0.90-1.10$, mild: fetal growth ratio $0.80-0.89$, moderate: fetal growth ratio $0.75-0.79$ and severe: fetal growth ratio $<0.75$. Proportionality: coefficient of bimodality and $z$ score for ponderal index $\left(P I=g / \mathrm{cm}^{3} \times 100\right)$. Neonatal mortality until discharge.

Results: < 3rd percentile: $13.5 \%(p<0.001)$; < 10th percentile: $31 \%(p<0.001)$; fetal growth ratio: $0.90 \pm 0.21$ ( $p<0.001$ ), mild restriction: $20.8 \%$, moderate restriction: $8.7 \%$ and severe restriction: $32.6 \%$. Coefficient of bimodality: 0.53 ; PI z score $<-1$ : $8 \%$. Maternal hypertensive disease was systematically associated with being small for gestational age (aOR 1.20,95\% CI 0.86-1.67), fetal growth ratio $\leq 0.89$ (aOR $1.71,1.24-2.36)$ and PI $z$ score < -1 (aOR 1.60, 1.03-2.41). Adjusted odds ratios for neonatal mortality were: 2.64 (95\% CI 1.71-3.92) for being small for gestational age, 2.76 (95\% CI 1.85-4.10) for fetal growth ratio $\leq 0.89$, and 1.37 (95\% CI $0.80-2.32$ ) for $z$ score PI $<-1$.

Conclusions: Small for gestational age, mostly symmetric and severe restriction is a frequent condition in $<1,500 \mathrm{~g}$ neonates and is associated with higher mortality rates.
\end{abstract}

J Pediatr (Rio J). 2005;81(3):198-204: Very low birth weight, small for gestational age, multicenter networks.

1. PhD. Researcher, School of Medicine, Universidade de Buenos Aires. Perinatal Epidemiology, Maternidade Sardá, Buenos Aires, Argentina.

2. Professor, School of Medicine, Pontificia Universidad Católica de Chile, Santiago, Chile.

3. Associate professor of Public Health, School of Medicine. Associate professor of Statistics, School of Mathmatics, Pontificia Universidad Católica de Chile, Santiago, Chile.

4. Collaborative centers and collaborators:

Argentina - Clínica e Maternidade Suíço-Argentina: Gabriel Musante, Hospital de Clínicas José de San Martín: Isabel Kurlat, Hospital Italiano: Gonzalo Mariani, Hospital Juan Fernández: Liliana Roldán, Hospital Lagomaggiore: Daniel Agost, Maternidade Ramón Sardá: Carlos Grandi, Sanatorio de la Trinidad: Marcelo Decaro.

Chile - Hospital Clínico Universidade Católica: Alberto Estay, Hospital Clínico Universidade do Chile: Rodrigo Ramírez, Hospital Guillermo Grant: Aldo Bancalari, Hospital Gustavo Fricke: Jane Standen, Hospital San José: Agustina Gonzalez, Hospital Sótero del Río: Angélica Alegría. Paraguay - Hospital de Clínicas de Assunção: José M. Lacarruba. Peru - Hospital Cayetano Heredia: Jaime Zegarra.

Uruguay - Hospital Pereyra Rossel: Rubén Panizza.

Manuscript received Sep 132004, accepted for publication Feb 232005.

Suggested citation: Grandi C, Tapia JL, Marshall G, Grupo Colaborativo NEOCOSUR. An assessment of the severity, proportionality and risk of mortality of very low birth weight infants with fetal growth restriction. A multicenter South American analysis. J Pediatr (Rio J). 2005;81:198-204.

\section{Introduction}

Intrauterine growth restriction (IGR) is defined as insufficient expression of genetic fetal growth potential. In general, any newborn infant (NI) whose birth weight is below the 10th percentile for the weight that corresponds to their gestational age is included. Such NI are classified as small for gestational age (SGA).

The importance of IGR is that those affected exhibited greater perinatal morbidity and mortality, ${ }^{1-3}$ reduced postnatal growth and an increased risk of compromised intellectual development ${ }^{4,5}$ and stillbirth during the next pregnancy. ${ }^{6}$ Furthermore, IGR has recently been linked to an increased probability of developing chronic diseases during adulthood, such as arterial hypertension, cardiovascular diseases and diabetes. ${ }^{7}$

A recent study of 11 neonatal intensive care units in four South American countries, ${ }^{8}$ found that $33 \%$ of the $38 \mathrm{NI}$ included whose birth weights were below $1,500 \mathrm{~g}$ were SGA.

In addition, SGA infants born live are also heterogeneous in terms of severity, i.e. the degree of growth restriction, and little is known about the impact on prognosis. 
Considerable interest has recently been generated in subdividing SGA infants into asymmetrical (wasted: normal length and head circumference for gestational age, but with low weight for length) and symmetrical (stunted: symmetrical reductions in weight, length and head circumference). The main reason for this classification is that there is some evidence that these two subtypes of growth restriction represent different etiologies, operate in different stages during pregnancy and have different prognostic significance. 9,10

In consequence, it is relevant to take account of the condition of SGA when analyzing the prognosis of NI with birth weights below $1,500 \mathrm{~g}$ in our region. All of these facts lead us to undertake wider-ranging studies with dependent variables being the condition of SGA, its severity and proportionality according to varying degrees of prematurity, which could be of use for establishing recommendations or interventions to better care for these NI.

The objectives of the present study were: 1 ) to evaluate the prevalence, severity and proportionality of NI weighing less than $1,500 \mathrm{~g}$ and SGA at varying degrees of prematurity and, 2) to estimate the risk of mortality according to SGA, degree of severity and proportionality.

\section{Methods \\ Population}

Between October 1997 and May 2003 all infants were prospectively enrolled if they were born weighing from 500 to $1,500 \mathrm{~g}$ at one of 16 neonatal units in South America (Argentina, Chile, Peru, Paraguay and Uruguay) that cooperate in a neonatal network (NEOCOSUR Collaborative Group). Data for the study was compiled at one of the centers which acts as a central database (Neonatology Department, Universidad Católica, Chile). Data is updated online via the Internet. Records include demographic characteristics, morbidity, mortality and interventions, permanently controlling the degree of data consistency. Cases involving transfers, the presence of lethal congenital malformations and chromosomal diseases were excluded.

This is an observational and analytical study of a historical cohort. Infants were defined as small for gestational age if birth weight was below the 10th percentile on a weight for postnatal gestational age curve from Argentina. ${ }^{11} \mathrm{Gestational}$ age was estimated (in completed weeks) from the first day of the last menstrual period and usually confirmed with ultrasound at the start of the second trimester. Prematurity, based on gestational age, was classed as extreme (24-28 weeks), moderate (29-32 weeks) and mild (33-36 weeks).

\section{Pre-established outcome measurements}

- Birth weight below the 3rd percentile.

- Birth weight below the 10th percentile (SGA).

- Severity: using the fetal growth ratio (FGR), defined as the ratio between the observed birth weight and the mean birth weight for each gestational age adapted from previously published standards. ${ }^{12}$ Infants were classed as having no growth restriction if FGR was between 0.90 and 1.10. Growth restriction was classed as mild: FGR 0.80-0.89; moderate: FGR 0.75-0.79 (below percentile 4.3) and severe, FGR $<0.75$ (percentile below 1.7). ${ }^{13}$ The cutoff point for the group without restricted growth (which includes $10 \%$ of the mean - FGR 1.00), represents a similar relative weight to that commonly utilized for identifying the optimal nutritional status level in older children and adults. The cutoff point for the group with restricted growth $(\leq 0.89)$ is approximately comparable with the conventional definition ( $<10$ th percentile). We used this approach because it provides important clinical information (weight percentage below the mean). ${ }^{14}$

- Proportionality: estimated by the $z$ score for ponderal index (PI $\left.=\mathrm{g} / \mathrm{cm}^{3} \times 100\right)$ and the coefficient of bimodality.

Ponderal index z-scores were computed as follows: the observed PI $\left(x_{i}\right)$ for each NI is subtracted from the mean $(X)$ and divided by the corresponding standard deviation (SD) of each gestational age from the curve adopted. ${ }^{11}$ Therefore the $\mathrm{z}$-score indicates the number of standard deviations by which the PI diverges from the mean. If the z-score was below - 1 (PI 1 SD below the average) this was defined as asymmetrical growth restriction. ${ }^{12}$ Due to the increasing variation in z-score, which theoretically could be caused by deviation (lack of symmetry), platykurtosis (flattened distribution curve) or bi or multimodality of frequency distribution, a coefficient of bimodality was calculated for PI for each gestational age using the ratio: $1+$ deviation $\wedge 2$ / kurtosis +3 . Values $<0.55$ indicate unimodal distribution - equivalent to symmetrical growth restriction - and values $\geq 0.55$ indicate bimodality - equivalent to asymmetrical growth restriction. ${ }^{12-15}$

- Neonatal mortality up to discharge: adjusted for gestational age. Potential confounding variables: gestational age, adolescence (mother younger than 18), control of pregnancy, multiple birth, hypertension induced by pregnancy (gestational hypertension and preeclampsia), diabetes and prenatal diagnosis of restricted growth (by two ultrasound fetal anthropometric indicators: rate of fetal abdominal circumference growth and ratio abdominal circumference/length of femur below the 10th percentile).

Any significant interaction between pregnancy-induced hypertension and intrauterine growth restriction would suggest that the effect of restriction on the results is modified by maternal hypertension.

\section{Statistical analysis}

Measures of central tendencies (mean, median or proportions, as applicable) and measures of distribution (standard deviation, first and third quartiles, 95\% confidence interval). In order to compare means, the Student $t$ tests and one way analysis of variance were used and to compare medians the Mann-Whitney test was employed. 
The $\chi^{2}$ test was utilized to compare proportions. Bivariate risk was calculated from the unadjusted odds ratio (OR) with $95 \%$ confidence interval. Finally, the population attributable risk (PAR) was calculated together with its $95 \%$ confidence interval.

The risks for a variety of adverse events, adjusted for potential confounding variables, was estimated using multiple logistic regression models (adjusted OR with $95 \%$ confidence intervals). The result of including birth weight in the models was colinearity.

Statistical significance was defined as $p<0.05$ (two tailed). Sample sizes for certain variables may produce small differences due to lack of data.

For all statistic analyses, Statistica (Version 5.1, Statsoft, Tulsa, OK) and Epidat 2.0 (PAHO/WHO and Xunta de Galicia) were used.

\section{Results}

One hundred and twenty-nine (6.9\%) of the 1,895 live births with weights below $1,500 \mathrm{~g}$ that had originally been included in the database were excluded because of lethal congenital anomalies or chromosomal syndromes, 77 (4.1\%) were excluded because their gestational ages were less than 24 weeks, three $(0.16 \%)$ because data on gestational age was missing and $132(7.1 \%)$ because length at birth was unknown. Thus, $1,518(81.6 \%)$ records made up the final sample and were included in the analysis.

The population's characteristics appear in Table 1 . Two thirds of mothers had undergone prenatal control (64\% received antenatal corticoids), with the elevated prevalence of arterial hypertension and IGR among mothers giving birth to SGA infants meriting special mention $(p<0.001)$. These infants were born more mature and lighter than those with appropriate weights $(p<0.001)$.

Two hundred and fourteen newborns (13.5\%; 95\% CI 11.8-15.3) presented birth weight below the 3rd percentile, while for birth weight below the 10th percentile this figure rose to 455 (30.7\%; 95\% CI 27.8-32.2), both positively correlated with increasing gestational age $\left(\chi^{2}\right.$ for linear trend, $\mathrm{p}<0.001$ ).

The mean FGR was $0.90(S D=0.21)$ and there was a significant $(p<0.001)$ tendency for FGR to reduce as gestational age increased (Figure 1 ). Fetal growth ratio values were below 0.76 in $32.6 \%$ (95\% CI 30-35.3, $\mathrm{n}=387$ ) of cases while $63 \%$ ( $95 \%$ CI $60-66.4, \mathrm{n}=734$ ) exhibited FGR $\leq 0.89$ which correlated positively with increasing gestational age ( $<<0.001$; Figure 2$)$.

The mean z-score was $0.007( \pm 1.01)$ and was lower for SGA $(-0.188 \pm 0.88$ versus $0.099 \pm 1.05 ; \mathrm{p}<0.0010)$. One hundred and twenty $(8 \%, 95 \%$ CI $6.6-9.3)$ of the NI with weights below $1,500 \mathrm{~g}$ presented PI z-scores below -1 (asymmetrical growth restriction), with this proportion being greater among SGA infants $(63 / 467,13.5 \%)$ when compared with children whose weights were appropriate $(57 / 1,051 ; 5.42 \%)(p<0.001)$. No differences in the rates of $z$-score $<-1$ were observed according to degree of prematurity ( $p=0.178)$. Furthermore, those preterms suffering from asymmetrical restriction exhibited more severe restriction (FGR $<0.75$ ) than did those with symmetrical restriction (OR 3.16, 95\% CI 2.1-4.7).

The coefficient of bimodality oscillated between -0.27 and 0.78 (mean 0.53 ) with no relation to gestational age, while mean PI was 2.26 (SD = 0.39). When compared with appropriate for gestational age children, SGA infants

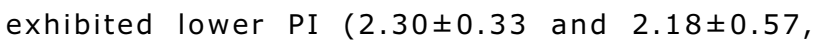
respectively, $\mathrm{p}<0.001)$.

In Table 2 it will be observed that the coefficient of bimodality reduced in line with severity of restriction, while the proportion of asymmetry increases with severity of growth restriction ( $p<0.001$ ).

Prenatal diagnosis of restricted growth and maternal arterial hypertension were the only conditions linked to an

Table 1 - Population's characteristics

\begin{tabular}{|c|c|c|c|c|}
\hline Characteristic & $\begin{array}{c}\text { Total } \\
(n=1,518)\end{array}$ & $\begin{array}{c}\text { SGA } \\
(n=467)\end{array}$ & $\begin{array}{c}\text { Non SGA } \\
(n=1,051)\end{array}$ & $\mathbf{p} *$ \\
\hline BW (g) mean (SD) & $1,113(260)$ & $1,077(290)$ & $1,129(244)$ & $<0.001$ \\
\hline GA (weeks) mean (SD) & $29.6(2.6)$ & $31.7(2.2)$ & $28.6(1.3)$ & $<0.001$ \\
\hline Male sex & $819(54 \%)$ & $256(55 \%)$ & $557(53 \%)$ & 0.716 \\
\hline Mother's age (years) mean (SD) & $27.3(7.2)$ & $27.7(7.0)$ & $27.1(7.6)$ & 0.130 \\
\hline Adolescent mother ( $\leq 18$ years) & $124(8.2 \%)$ & $45(9.6 \%)$ & $142(13.5 \%)$ & 0.013 \\
\hline Prenatal control & $1,145(75.4 \%)$ & $344(7.6 \%)$ & $800(76.2 \%)$ & 0.278 \\
\hline Multiple birth & $264(17.4 \%)$ & $90(19.2 \%)$ & $174(16.5 \%)$ & 0.199 \\
\hline Diabetes & $35(2.3 \%)$ & $12(2.5 \%)$ & $22(2.1 \%)$ & 0.625 \\
\hline Hypertension & $466(30.7 \%)$ & $208(44.5 \%)$ & $259(24.6 \%)$ & $<0.001$ \\
\hline IGR & $559(36.8 \%)$ & $348(74.5 \%)$ & $211(20 \%)$ & $<0.001$ \\
\hline
\end{tabular}

* Comparison between SGA and non SGA.

$\mathrm{SGA}=$ small for gestational age $\left(<10^{\text {th }}\right.$ percentile $) ; \mathrm{BW}=$ birth weight $\mathrm{SD}=$ standard deviation; $\mathrm{GA}=$ gestational age; $I G R=$ intrauterine growth restriction (diagnosis by prenatal ultrasound). 
increased risk of being small for gestational age and having FGR $\leq 0.89$, with elevated PAR values meriting attention (Tables 3 and 4), while the condition of adolescence revealed a mild protective effect, although not a statistically significant one. The slight increase in risk in the absence of prenatal control, while statistically significant, did not correlate with a transcendent impact at the population level.

Once more, maternal hypertension (aOR 1.60, 95\% CI 1.03-2.04) and intrauterine growth restriction (aOR 1.80, $95 \%$ CI 1.16-2.82) were the only variables that remained statistically associated with the condition of asymmetrical growth restriction with a discrete repercussion at the population level (PAR $=17 \%$ [95\% CI 4-30] and $24 \%$ [95\% CI 9-39], respectively).

Small for gestational age or severely growth restricted infants born at weights below $1,500 \mathrm{~g}$ exhibited a risk of death more than double that of those who did not present these conditions $(p<0.05)$. No prenatal characteristic or



Figure 1 - Fetal growth ratio (FGR) according to gestational age

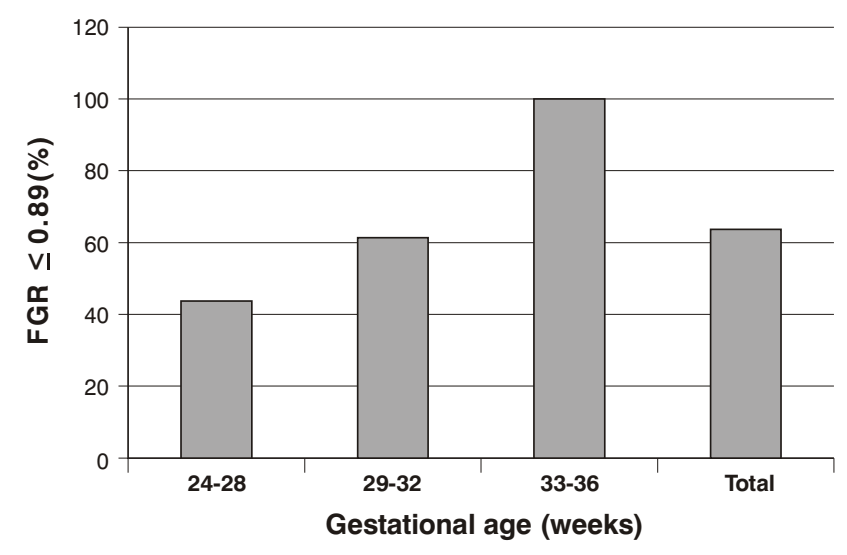

FGR: Fetal Growth Ratio.

Figure 2 - Severity of growth delay (FGR $\leq 0.89)$ according to prematurity levels pathology was associated with a biological risk and/or statistically altered risk of mortality, with the exception of the absence of prenatal, control, which exhibited a significantly elevated risk with similar magnitude for each of the three outcomes $(p<0.05)$, suggesting delayed detection and treatment of medical and/or obstetric complications during pregnancy (Table 5). As would be expected, for every extra week that pregnancy lasts the risk of death reduces by 30 to $40 \%$ ( $p<0.05)$.

When FGR was processed in a continuous manner, the risk of neonatal mortality increased by 0.027 times for every 0.10 units that FGR reduced ( $95 \%$ CI $0.009-0.07$, $\mathrm{p}<0.001)$.

\section{Discussion}

The present study, based on a hospital sample from 16 neonatal units at 16 Latin American university hospital maternity units, demonstrates that the prevalence of the condition of being small for gestational is elevated among preterms born with weights below $1,500 \mathrm{~g}$ and that the condition is severe in a third of such infants. The condition is inversely related to gestational age and is linked with an elevated risk of mortality. The characteristic of asymmetry conferred little additional risk to that already generated by the degree of restriction severity.

Among the differentiating features of our study, it is worth mentioning that this is the first exploration of this problem in our region, describing FGR and PI in preterms and employing standardized data collection and accruing a large sample size. In contrast with other studies, ${ }^{16}$ the sample was not limited by gestational age.

A number of limitations can be listed. Several different authors ${ }^{17}$ have proposed that postnatal weight curves based on an estimate of gestational age calculated from the date of the last menstrual period overestimate gestational age and thus underestimate the prevalence and severity of compromised growth in preterms. Ott, ${ }^{18}$ suggests that standards for birth weight based on fetal growth gauged by ultrasound and adjusted for maternal variables ${ }^{19}$ offer better predictive value for abnormal outcomes. Until a local standard is developed by ultrasound we consider that the findings are sufficiently representative of the study population.

In view of the elevated prevalence of absent prenatal control and in the face of the possibility of selection bias, all of the logistic models were re-analyzed with cases where there was no prenatal control excluded with no changes in the OR resulting, and superimposed confidence intervals being observed (data not shown).

The absence of bimodality (coefficient $<0.55$ and low prevalence of $z$-score $<-1$ ) is strong evidence against the existence of two different IGR subtypes (symmetrical vs asymmetrical), even in the most severe subsets.

Several different studies have linked fetal growth restriction with neonatal morbidity and mortality of preterms born weighing less than $1,500 \mathrm{~g}^{1-5,13,20-22}$ although without contemplating, as does the present study, severity and 
proportionality. Both the diagnosis and severity of growth restriction were associated (as expected) with a high risk of neonatal death, with absence of prenatal control being the only preceding factor that was potentially controllable to be systematically associated with death for the three outcomes investigated (SGA, FGR $<0.89$ and $z$-score $<-1$ ).

Table 2 - Coefficient of bimodality and ponderal index z-score according to IGR severity (excluding multiple birth; $\mathrm{n}=1,231$ )

\begin{tabular}{|c|c|c|c|c|c|}
\hline \multirow{3}{*}{$\begin{array}{c}\text { IGR severity } \\
\text { (FGR) }\end{array}$} & \multirow{3}{*}{$\mathbf{n}$} & \multirow{3}{*}{$\begin{array}{l}\text { Coefficient of } \\
\text { Bimodality }\end{array}$} & \multicolumn{3}{|c|}{ z-score } \\
\hline & & & \multirow[t]{2}{*}{ Mean * } & \multicolumn{2}{|c|}{$<-1+$} \\
\hline & & & & $\%$ & CI 95\% \\
\hline $0.90-1.10(\mathrm{No})$ & 501 & 0.53 & 0.19 & 5.1 & $3.3-7.6$ \\
\hline $0.80-0.89$ (Mild) & 335 & 0.48 & 0.02 & 6.4 & $3.8-10.4$ \\
\hline 0.75-0.79 (Moderate) & 90 & 0.22 & -0.26 & 13.4 & $7.7-21.8$ \\
\hline$<0.75$ (Severe) & 305 & 0.20 & -0.22 & 15.2 & $11.8-19.2$ \\
\hline
\end{tabular}

IGR = intrauterine growth restriction (IGR) evaluated by FGR (fetal growth ratio).

* Analysis of variance: $F=13.80(p<0,001)$.

$\dagger \chi^{2}$ for linear tendency $=29.4(p<0.001)$.

Table 3 - Unadjusted, adjusted, and population attributable risks of children small for gestational age according to maternal variables

\begin{tabular}{lccc}
\hline Covariate & OR (CI 95\%) & aOR (CI 95\%) * & PAR (CI 95\%) \\
\hline Adolescent mother & $0.68(0.46-0.98)$ & $0.62(0.37-1.03)$ & $-4(-8$ a 0$)$ \\
Controlled pregnancy & $1.26(0.95-1.66)$ & $1.40(0.94-2.0)$ & $4(0$ a 10$)$ \\
Multiple birth & $1.22(0.91-1.63)$ & $1.26(0.84-1.88)$ & $3(-1$ a 8$)$ \\
Diabetes & $1.17(0.54-2.49)$ & $1.80(0.69-4.79)$ & $0(-1$ a 2$)$ \\
Mother's hypertension & $2.27(1.79-2.88)$ & $1.20(0.86-1.67)$ & $25(18$ a 31$)$ \\
IGR & $12.47(9.5-16.3)$ & $7.41(5.4-10.1)$ & $70(65$ a 75$)$
\end{tabular}

$\mathrm{OR}=$ odds ratio; PAR = population attributable risk; IGR = intrauterine growth restriction (prenatal diagnosis by ultrasound).

* Adjusted risk for multiple logistic regression for the covariates listed and gestational age.

$\mathrm{n}=1,387 \quad-2{ }^{*} \log ($ likelihood $)=1081 \quad \chi^{2}(7)=634(\mathrm{p}<0.001)$.

Correct predictive value of $S G A=65 \%$.

No interaction between mother's hypertension and IGR was found. $(p=0.781)$

Table 4 - Unadjusted, adjusted, and population attributable risks of the fetal growth ratio $\leq 0.89$ according to maternal variables

\begin{tabular}{lccc}
\hline Covariate & OR (CI 95\%) & aOR (CI 95\%) $*$ & PAR (CI 95\%) \\
\hline Adolescent mother & $0.86(0.62-1.17)$ & $0.77(0.49-1.20)$ & $-1(-5$ a 2$)$ \\
Absence of prenatal control & $1.41(1.08-1.84)$ & $1.85(1.29-2.66)$ & $6(1$ a 11$)$ \\
Multiple birth & $1.17(0.88-1.54)$ & $1.15(0.80-1.17)$ & $2(-1$ a 7$)$ \\
Diabetes & $0.54(0.25-1.13)$ & $0.43(0.16-1.15)$ & $-1(-3$ a 0) \\
Mother's hypertension & $3.09(2.43-3.93)$ & $1.71(1.24-2.36)$ & $28(23$ a 33) \\
IGR & $14.1(11.2-19.5)$ & $10.42(7.5-14.4)$ & $59(55$ a 62)
\end{tabular}

$\overline{\mathrm{OR}}=$ odds ratio; PAR = population attributable risk; IGR = intrauterine growth restriction (prenatal diagnosis by ultrasound).

* Adjusted risk for multiple logistic regression for the covariates listed and gestational age.

$\mathrm{n}=1,387 \quad-2{ }^{*} \log ($ likelihood $)=1229 \quad \chi^{2}(7)=691(p<0.001)$

Correct predictive value FGR $\leq 0.89=78 \%$.

No interaction between mother's hypertension and IGR found. $(p=0.096)$. 
Table 5 - Adjusted neonatal mortality risks (confidence interval of 95\%) in SGA, FGR $\leq 0.89$ and z-score for ponderal index $<-1$ (multivariate analysis by logistic regression)*

\begin{tabular}{|c|c|c|c|}
\hline & \multicolumn{2}{|r|}{ Condition } & $z$-score $<-1$ \\
\hline $\begin{array}{l}\text { Exposition variable } \\
(1: \text { Yes; } 0: \text { No })\end{array}$ & $2.64(1.71-3.92)$ & $2.76(1.85-4.10)$ & $1.37(0.80-2.32)$ \\
\hline Covariate & & & \\
\hline $\begin{array}{l}\text { Adolescent mother } \\
\text { (1: Yes; 0: No) }\end{array}$ & $1.44(0.92-2.25)$ & $1.45(0.92-2.27)$ & $1.30(0.83-2.01)$ \\
\hline $\begin{array}{l}\text { Absence of prenatal cont } \\
(1: \text { Yes; } 0: \text { No })\end{array}$ & $2.66(1.86-3.81)$ & $2.56(1.78-3.68)$ & $2.74(1.98-3.98)$ \\
\hline $\begin{array}{l}\text { Multiple birth } \\
\text { (1: Yes; 0: No) }\end{array}$ & $0.98(0.63-1.52)$ & $0.94(0.61-1.45)$ & $0.96(0.63-1.46)$ \\
\hline $\begin{array}{l}\text { Diabetes } \\
\text { (1: Yes; 0: No) }\end{array}$ & $1.22(0.48-3.10)$ & $1.48(0.58-3.76)$ & $1.31(0.51-3.32)$ \\
\hline $\begin{array}{l}\text { Mother's hypertension } \\
\text { (1: Yes; 0: No) }\end{array}$ & $0.80(0.55-1.16)$ & $0.72(0.48-1.03)$ & $0.80(0.55-1.18)$ \\
\hline $\begin{array}{l}\text { IGR } \\
\text { (1: Yes; 0: No) }\end{array}$ & $1.20(0.79-1.80)$ & $1.04(0.69-1.57)$ & $1.65(1.15-2.4)$ \\
\hline Gestational age (weeks) & $0.62(0.58-0.67)$ & $0.62(0.58-0.69)$ & $0.65(0.60-0.69)$ \\
\hline
\end{tabular}

SGA = small for gestational age; FGR = fetal growth rate; $z$-score: ponderal index;

IGR = intrauterine growth restriction (prenatal diagnosis by ultrasound).

No interaction between mother's hypertension and IGR was found ( $p=0.653,0.953$ and 0.660 for SGA,

FGR $\leq 0.89$ and $z$-score $<-1$, respectively).

Right predictive values of models $=24.1,26.1$ and $20.7 \%$ for SGA, FGR $<0.89$ and $z$-score $z<-1$, respectively.

Maternal arterial hypertension and prenatal restricted growth diagnosis were the only maternal variables systematically and statistically associated with an increased risk for the three outcomes. It is important to point out the absence of interactions between these two variables, suggesting that each has an independent effect on the outcomes established. The magnitude of the PAR values associated with arterial hypertension and growth restriction are probably a reflection of the elevated prevalence of the two nosological entities among the study population (30.7 and $36.8 \%$, respectively).

The etiology of premature delivery is plurifactorial, but the many different maternal diseases and pregnancy-related conditions that limit fetal growth and contribute to the chance of adverse events among more mature fetuses may also have an effect on the growth and birth weights of very premature infants. ${ }^{20}$

The pathophysiology of restricted growth in fetuses destined to be born preterm is explained by a reduction in uterine flow and placental perfusion. This would promote a reduction in hormones that induce fetal growth, increasing cortisol and stimulating the myometrium, with the consequent triggering of labor and premature delivery. The activation of compensatory mechanisms can lead two one of two outcomes: 1) if they fail then stillbirth occurs and 2) if they are successful, growth is restricted and adaptation takes place. If this is sufficient the result will be a small for gestational age fullterm infant and, if insufficient, the mechanisms of labor will be activated and the preterm may survive. ${ }^{23}$

Only one study 16 agrees with ours about the fact that SGA prevalence, and also severity, increase with advancing gestational age, in contrast with other authors. In a study that included 4,700 preterms, Zeitlin et al. concluded that the relationship between restricted growth and premature delivery was strongest before 34 weeks' gestation. ${ }^{24}$ Another population study, ${ }^{25}$ found that the prevalence of restriction increased up to the thirtieth week $(12.3 \%)$ and then quickly decreased. Finally, in one study that enrolled 8,663 singleton infants, the proportion of SGA infants ( $<2$ SD from the mean) reduced from $21 \%$ between 26 and 30 weeks to $11.1 \%$ from 31 to 37 weeks. ${ }^{26}$ These discrepancies may be the result of sample size, policies on inducing labor, gestational age estimation, SGA definition, cutoff points for weight or gestational age among those under $1,500 \mathrm{~g}$ and termination of pregnancy. Owen et al., in a contrastive article comparing spontaneous and induced premature deliveries did not find any significant difference in neonatal outcomes. 27

Our values for PI agree with data published by other authors. ${ }^{13,28}$ Employing this indicator, the most common type of growth restriction was symmetrical. In common with the majority of developing countries, this can be attributed to its association with greater severity and increased prevalence of certain risk factors (for example a very small mother). 29 
We conclude that the prevalence of the condition of small for gestational is elevated among preterm infants born with birth weights below $1,500 \mathrm{~g}$ and that when this is very severe, irrespective of the cause, there is a high risk of mortality. Asymmetric growth restriction confers very little additional risk to that already conferred by the degree of restriction severity. We suggest an early test for restricted growth during prenatal control.

\section{References}

1. Lackman F, Capewell D, Richardson B, da Silva O, Gagnon R. The risks of spontaneous preterm delivery and perinatal mortality in relation to size at birth according to fetal versus neonatal growth standards. Am J Obstet Gynecol. 2001;184:946-53.

2. Bukowski R, Gahn D, Denning J, Saade G. Impairment of growth in fetuses destined to deliver preterm. Am J Obstet Gynecol. 2001; 185:463-7

3. Piper J, Xenakis E, McFarland M, Elliot B, Berjus M, Langer O. Do growth- retarded premature infants have different rates of perinatal morbidity and mortality than appropriately grown preterm infants? Obstet Gynecol. 1996;87:169-74.

4. Vik T, Markestad T, Ahlsten G. Body proportions and early neonatal morbidity in small for gestational age infants of successive births. J Reprod Med. 1997;42:88-90.

5. Newnham J. Consequences of fetal growth restriction. Curr Opin Obstet Gynecol. 1998;10:145-9.

6. Surkan PJ, Stephanson O, Dickman PW, Cnattingius S. Previous preterm and Small-for-Gestational-Age births and the subsequent risk of stillbirth. N Engl J Med. 2004;350:777-85.

7. Barker DJ, Gluckman PD, Godfrey KM, Harding JE, Owens JA, Robinson JS. Fetal nutrition and cardiovascular disease in adult life. Lancet. 1993;341:938-41.

8. Grupo Colaborativo Neocosur. Very low birth weight infants outcome in 11 Southamerican NICU's. J Perinatol. 2002;22:2-7.

9. Miller $\mathrm{H}$, Merrit T. Fetal growth in humans. Chicago, IL: Year Book Medical Publishers; 1979.

10. Bardin C, Zelkowitz P, Papageoirgiu A. Outcome of small for gestational age and appropriate for gestational age infants born before 27 weeks of gestation. Am J Obstet Gynecol. 1998;178:658-69.

11. San Pedro M, Grandi C, Larguía M, Solana C. Estándar de peso para la edad gestacional en 55706 recién nacidos sanos de una maternidad pública de Buenos Aires. Medicina (Buenos Aires). 2001;61:15-22.

12. Kramer M, McLean F, Olivier M, Willis D, Usher R. Body proportionality and head and length 'sparing' in growth-retarded neonates: a critical reappraisal. Pediatrics. 1989;86:717-23.

13. Kramer MS, Olivier M, McLean FH, Willis DM, Usher RH. Impact of intrauterine growth retardation and body proportionality on fetal and neonatal outcome. Pediatrics. 1990;86:707-13.
14. Sanderson $D$, Wilcox $M$, Johnson I. The individualized birthweight ratio: a new method of identifying intrauterine growth retardation. $\mathrm{Br}$ J Obstet Gynaecol.1994;101:310-14.

15. SAS User's Guide, Version 5 Ed. Cary, NC: SAS Institute Inc; 1985.

16. Largo R, Siebenthal K, Etter K, Morales C, Bucher H, Due G. Body proportionality in growth-retarded VLBW infants. J Perinat Med. 1997; $25: 17-25$.

17. Grandi C, Luchtenberg G, Rojas E. Are neonatal growth standards adequate for the diagnosis of fetal growth restriction in preterm babies? [abstract] Pediatr Res. 2003;53:873.

18. Ott $W$. Intrauterine growth retardation and preterm delivery. Am J Obstet Gynecol. 1993;168:1710-5.

19. Gardosi J, Mongelli M, Wicox M, Chang A. An adjustable fetal weight standard. Ultrasound Obstet Gynecol. 1995;6:168-74.

20. Spinillo A, Capuzzo E, Piazzi G, Baltaro F, Stronati M, Ometto A. Significance of low birthweight for gestational age among very preterm infants. Br J Obstet Gynaecol. 1997;104:668-73.

21. Bernstein IM, Horbar J, Badger G, Ohlsson A, Golan A. Morbidity and mortality among very-low-birth-weight neonates with intrauterine growth restriction. Am J Obstet Gynecol. 2000;182:198-206.

22. Regev R, Lusky A, Dolfin T, Litmanovitz I, Arnon S, Reichman B. Excess mortality and morbidity among small-for-gestationalage premature infants: a population-based study. J Pediatr. 2003; 143:186-91.

23. Hediger M, Scholl T. Fetal growth and the etiology of preterm delivery. Obstet Gynecol. 1995;85:175-82.

24. Zeitlin J, Ancel P, Saurel-Cubizolles M, Papiernik E. The relationship between growth restriction and preterm delivery: an empirical approach using data from an European casecontrol study. Br J Obstet Gynaecol. 2000;107:750-8.

25. Gilbert W, Danielsen B. Pregnancy outcomes associated with IUGR. Am J Obstet Gynecol. 2003;188:1596-601.

26. Maršál K, Persson $P$, Larsen $T$, Lilja H, Selbing A, Sultan B. Intrauterine growth curves based on ultrasonically estimated fetal weights. Acta Paediatr. 1996;85:843-8.

27. Owen J, Baker S, Hauth J, Goldenberg R, Davis R, Copper R. Is indicated or spontaneous preterm delivery more advantageous for the fetus? Am J Obstet Gynecol. 1990;163:868-72.

28. Vintzileos A, Lodeiro J, Feinstein S, Campbell W, Weinbaum $P$, Nochimson D. Value of fetal ponderal index in predicting growth retardation. Obstet Gynecol. 1986;67:584-8.

29. Villar J, Altobelli L, Kestler E, Belizán J. A health priority for developing countries: the prevention of chronic fetal malnutrition. Bull WHO. 1986;64:847-51

Correspondence:

Carlos Grandi

Cabello 3150 (1425), 70 B

Buenos Aires, Argentina

Tel.: +54 (11) 4803.7622 - Fax: +54 (11) 4943.7779

E-mail: cgrandi@intramed.net 